\title{
Alcohol Abuse as a Militating Factor against Quality of Life for Migrants' Youth Population in Selected Provinces of South Africa
}

\author{
F.K. Matlakala ${ }^{1, *}$, J.C. Makhubele ${ }^{1}$, D.T. Masilo ${ }^{1}$, M.M. Kwakwa ${ }^{1}$, T.V. Baloyi ${ }^{2}$, A. Mabasa ${ }^{2}$, \\ N.E. Rabotata ${ }^{1}$ and P. Mafa ${ }^{1}$ \\ ${ }^{1}$ University of Limpopo, Department of Social Work, South Africa \\ ${ }^{2}$ University of Venda, Department of Social Work, South Africa
}

\begin{abstract}
Migrants' youth are seen as one of the vulnerable populations in South Africa. This is largely due to the fact that they are seen as people who come to take job opportunities of the youth in the host country. In order to cope with their fear and stress, migrants indulge in binge consumption of alcohol. It is in light of that that in this paper researchers aimed to accentuate alcohol abuse as a militating factor against the quality of life for migrants' youth population in selected provinces of South Africa. The study adopted qualitative approach and case study design to highlight how alcohol is seen as a militating factor against quality of life. The study population was drawn from three provinces in South Africa using convenient sampling technique to sample three participants. Moreover, the data was collected telephonically in three selected provinces and analysed thematically. The findings indicate that due to the accessibility, availability, affordability and stress migrants' youth indulge in binge consumption. Thus, researchers recommend that policymakers should make guidelines that will restrict mushrooming of alcohol outlets - be regulation to prohibit overcrowding of outlets in selected provinces of South Africa.
\end{abstract}

Keywords: Alcohol, migrants, youth, accessibility, affordability, stress.

\section{INTRODUCTION AND BACKGROUND INFOR- MATION}

In South Africa, migrants are seen as the most vulnerable population to all sort of violence. As a result of violence that is perpetuated by natives, migrants continues to live in constant fear for their lives. Considering that, some migrants resort to alcohol abuse to deal with their fear, fit into a host country and/or gain acceptances from the natives in their new communities (Leow, Goldstein and McGlinchy 2006). What should be underscored is that over-indulgence of alcohol lead to psychological disorders such as trauma, posttraumatic stress disorder and depression (Horyniak, Melo, Farrell, Ojeda, and Strathdee 2016). In terms of trauma, the Center for Victims of Torture indicated that trauma experienced by migrants can be understood in three-fold. Firstly, migrants experience trauma as a result of intimidation, harassment, illness and witness of violence in the host country. Secondly, migrants experience trauma as a result of fear to robbery or exploitation. Lastly, migrants experience trauma due to family challenges back from home and language barrier with the host community (Center for Victims of Torture 2015). On that score, it could be deduced that trauma causes migrants to experience mental and emotional distress and alcohol is seen as coping strategy. A case in point, a study in Finland found that the Rwandan migrants engages in binge

*Address correspondence to this author at the University of Limpopo, Department of Social Work, South Africa; E-mail: fransmatlakala@gmail.com drinking of alcohol as a coping mechanism/escapism (Idemudia and Boehnke 2020).

Subsequent to the above, migrants' abuse alcohol due to the number of outlets available in communities. On that note, high density of alcohol outlets contributes to higher consumptions of alcohol, in this instance, migrants (Connor, DeBord, Pretty, Oliver, Roth, Lees, Krieg, Rogers, Escalante, Toennis, Clark 2010; Matlakala and Makhubele 2019). The situation is dire in South Africa, as alcohol is easily available and affordable which offers migrants with variety of option to choose from (Peltzer, Ramlagan, Johnson, and Phaswana-Mafuya 2010, Osuafor, Maputle and Ayiga 2016). What comes out is that migrants' abuse alcohol due to its accessibility and affordability in the host country. This has seen migrants' youth being able to afford alcohol to address some of social ills that they face, one being xenophobic attacks from the natives. On that score, it could be deduced that the increment of pricing on alcohol leads to the decreases of consumptions (Anderson and Baumberg 2006). Even when that is the case, it has been reported that when youth fails to afford expensive alcohol, they resolve to cheaper alcohol, such as Blacklabel, that will maximise their intake (Gruenewald and Remer 2006; Matlakala 2018; Matlakala and Makhubele 2019).

Similarly, over a decade ago, Makhubele (2012) pointed out that poverty pushes individuals to indulge in binge drinking. Subsequently to that due to low socioeconomic factors and loneliness, individuals find 
themselves pressurised and resort to binge drinking (Setlalentoa, Ryke and Strydom 2015). In essence, poverty and unemployment are the contributing factors that predispose individuals to alcohol abuse. With that being said, to respond to the pressure of not being able to find employment, individuals find themselves hanging out in alcohol outlets and end up testing alcohol, subsequently making alcohol a habit and migrants are not exception. The downfall of indulging into binge drinking is that most migrants find themselves in conflict with the law (Ananias, Makhubele, Hasheela, Hamuse, Freeman, Mafa, Matlakala, Chilwalo, Rapholo and Svinurai 2019; Mafa and Makhubele 2020). On that score, their actions which were militated by alcohol might cause them to be deported back to their native country. To that end, this paper is aimed at highlighting alcohol abuse as a militating factor against quality of life of migrants' population in selected provinces of South Africa.

\section{THEORETICAL FRAMEWORKS}

This study adopted two theories being ecosystems theory and migration systems theory. The ecosystems theory views an individual who belongs to a system, being environment and/or community (Karger 2000). In light of that, the ecosystems theorists propound that family and environment should not be ignored when accentuating factors that contribute to alcohol abuse amongst the youth. On that score, this theory was chosen due to its ability to give an understanding of the interdependence of systems in the environment. Moreover, this theory looks at the mutual relationship between an individual and his or her relationship with the community. Moreover, when positioning the ecosystems theory on possible solutions to mitigate the effect of binge consumption amongst youth, the theory advocates for the holistic approach method of intervention (Setlalentoa et al. 2015). In essence, migrants' youth challenge of binge consumption should be viewed in conjunction to the environment they find themselves at. In that note, binge drinking could be as a result of high density of alcohol outlets in the community (Hasheela, Makhubele, Ananias, Matlakala, Mafa, Chiwalo, Rapholo, Freeman, Svinurai, and Hamuse 2019). On that score, an intervention to an individual and returning them to an environment with abundance of alcohol is a recipe to relapse. In light of that, migrants cannot attain quality of life as a result of alcohol abuse.

On the other hand, Migration Systems Theory assume that migrants contribute to change in the economic, social, cultural and institutional conditions in both the receiving and sending country (Castles and Miller 2003). In terms of economic development, migrants continue to purchase legal alcohol and thus contribute to the tax revenues of the host country. Similarly, in terms of social development, as they hang out in taverns they establish social ties with their peers in the host countries. But the bottom-line is that, whilst contributing to the economy of the host country, migrants' youth do not access quality of life for their own due to alcohol abuse.

\section{RESEARCH METHODS}

The researchers opted for qualitative research approach in order to gain a valuable knowledge and first-hand information on alcohol abuse as a militating factor against the quality of life for migrants' in Mpumalanga, North-West and Gauteng Provinces. The researchers chose these provinces as they are entry points for migrants from neighbouring countries in Africa such as Mozambique, eSwatini and Botswana as well as the rest of the continent and beyond.

The researchers adopted a case study design operating within descriptive research due to its ability to enable the researchers to gain a broader understanding and describe how alcohol abuse is a militating factor against the quality of life of migrants' population in selected provinces in South Africa in detail (Bless and Higson-Smith 2000; Neuman 2000). The population for this study were drawn from migrants' youth in Nkomazi (Mbuzini), Mahikeng and Tembisa. The researchers opted for convenient sampling technique to sample six participants (two from each province). Due to the Covid-19 pandemic, data was collected telephonically using an individual semistructured interview until the level saturation. Data was analysed thematically using thematic analysis. Ethics were adhered to as researchers explained the consent form and that their participations was voluntarily.

\section{FINDINGS AND DISCUSSION}

In this study, there were several themes that emerged during data collection with the aid of semistructured interviews. The emerged themes are presented and analysed herein.

\subsection{Accessibility and Availability of Alcohol}

Alcohol use and abuse is a matter of choice. The researchers are aware that human body requires alcohol (Paton 2005), as such, they are not arguing 
that fact, but they speak of abuse of alcohol that militate against the quality of life in migrant youth. Evidently, there are numerous alcohol outlets that are mushrooming in rural communities globally and South Africa is not an exception (Hasheela et al. 2019; Hasheela, Ananias and Schenek 2020). In light of that, participants in this study shared the sentiments that there is accessibility and availability of alcohol in their place of residence as migrants.

"There are many alcohol outlets in our area... As migrants, we drink a lot, even with curfew in place, we remain unshaken." (Participant 4, Gauteng Province)

Sharing similar view, another participant echoed that:

"We have so many taverns and they are in close proximity with $20 \mathrm{~m}$ apart from each other." (Participant 2, Mpumalanga Province)

In addition, another participant stated that:

"They are many taverns in Mafikeng which are close to each other. In the villages they are approximately 5 metre away from each other." (Participant 6, North West Province)

The researchers found that migrants' youth tend to indulge into alcohol due to the availability and accessibility. One of the participants, as seen above, stipulated that there is 5 metre distance of alcohol outlets in their area. In most cases, those who sell illegal alcohol, such as home-brewed alcohol uses traditional ceremonies to make their product known and sold. For that reason, it becomes clear that migrants are spoilt for a choice of choosing alcohol that will quest their thirst, be it legal and/or illegal alcohol. What researchers are underscoring being that, when migrants over-indulge in alcohol, they engage in risky sexual behaviour and thus putting their status at risk of being arrested in the host country (Peltzer and Pengpid 2008; Idemudia and Boehnke 2020). In essence, instead of acquiring the quality of life that they sought for in the host country, migrants' youth find themselves behind bars due to criminal activities that they committed when they were intoxicated. The findings in this study re-emphasis one of the tenants of the ecosystems theory which emphasis the interdependence of systems. Accordingly, the ecosystems hold the notion that the environment influences the behaviour of migrants' youth and vice versa (Weyers 2012). In light of that, in this study it became evident that the abundance of alcohol in an environment influences youth to indulge in binge consumption.

Moreover, when positioning the ecosystems theory on possible solutions to mitigate the effect of binge consumption amongst youth, the theory advocates for the holistic approach method of intervention (Setlalentoa et al. 2015). In essence, migrants' youth challenge of binge consumption should be viewed in conjunction to the environment they find themselves at. Intervention to an individual and returning them to an environment with abundance of alcohol is a recipe to relapse. In light of that, migrants cannot attain quality of life as a result of alcohol abuse. By and large, one may argue using migration systems theory that migrants have positive influence in the economic and social development of the host country. Thus, researchers recommend that policymakers should make guidelines that will restrict mushrooming of alcohol outlets - be regulation to prohibit overcrowding of outlets in selected provinces of South Africa.

\subsection{Affordability of Alcohol}

Most of the migrants leave their country of origin due to unemployment and poverty in a search for better life in other countries. However, a new phenomenon emerged in this study, that is, some migrants leave their country or origin due to the affordability of alcohol in the host country, in this instance, South Africa (Setlalentoa, Pisa, Thekisho, Ryke, and Loots Du 2010). For instance, in this study, one of the participants indicated that he left his country of origin (Botswana) to access affordable alcohol in South Africa. That goes to show that the affordability of alcohol guard against quality of life for most migrants. In other words, instead of moving to South Africa, work and send money home, some migrants' youth compromise their life and spend huge sum of money on alcohol. Some of the participants shared the following sentiments:

"South African alcohol is affordable and alcohol outlets operate for long hours as compared to those of Botswana. Moreover, we prefer buying alcohol from taverns as it is cheap and affordable as compared to Pubs wherein the alcohol is expensive and dictates on the kind of attire one has to put on. In taverns we wear casual whereas in pubs one has to 
wear formal." (Participant 3, North West Province)

Another migrant shared that:

"Many people prefer to purchase alcohol at Macro outlet as it is cheap and affordable." (Participant 1, Gauteng Province)

On other hand, another participant acknowledges that due to released measures in the boarder, they are able to access alcohol from another country. The migrant stated that:

"Alcohol is very affordable.... We also have to an easy access of alcohol and during lockdown, we used to smuggle it from eSwatini [formerly known as Swaziland]" (Participant 5, Mpumalanga Province)

The fact that affordability works against the quality of life of migrants is beyond doubt. It is for that reason that several countries have adopted higher tax strategies on alcohol (Anderson and Baumberg 2006). These came after World Health Organisation underscored that higher taxation on drugs serves as one of the prevention methods for alcohol abuse (WHO 2002; 2019). South Africa has seemingly followed suit, as in most of the budget speech, the Minister of Finance highlights the importance of increasing tax on products that affects the wellbeing, and drugs are not an exception. Whether the strategy on increment of tax on alcohol is working or not it remains to be tested. However, several authors have also come out to support the increment of tax on alcohol in lessening the drug problem (Collins and Lapsley 2008; Peltzer and Pengpid 2008; Weyers 2012; Ramlagan, Peltzer, and Phaswana-Mafuya 2013). Be that as it may, an increment of taxing of alcohol makes youth to resort to other avenues to quest their thirst by resolving into other means, such as home brewed alcohol due to its affordability. Thus, the researchers recommend the tightening of policies that will prohibit illegal alcohol to be sold at black markets.

\subsection{Stress}

Youth see alcohol as a way of dealing with stress encountered in the host country. In most instance, migrants find themselves unable to adapt to the new environment and be home sick (Idemudia and Boehnke 2020). As a result of that, those migrants develop stress and see alcohol as a way to deal with their stress. Moreover, alcohol also assist them to also fit in the host country. But that does not mean that all migrants indulge into alcohol due to the inability to adapt to the host country, others resolve into alcohol due to stress of inability to secure an employment for their livelihood. Accordingly, in this study, migrant youth indulge into binge drinking in order to cope with the stress caused by the loss of the loved one in the sending country and inability to secure an employment in the host country. Some of the narratives shared are as followed:

"Sometimes we take alcohol due to stress of not securing a job for our livelihood". (Participant 3, North West Province)

On the other hand, the other participant shared that:

"When I lost my sister, I experimented with home-brewed alcohol fomented from Mozambique. That beer was very strong as it made me to see the world spinning. The purpose was to assist me to cope with the loss of my sister in my country [Zimbabwe]. It was a stressful event for me". (Participant 4, Gauteng Province)

On the same vein, another echoed that:

"Alcohol take all the stress that we are having. It stimulates us and make us to have a good self-esteem". (Participant 2, Mpumalanga Province)

Adapting to new environment comes with its own challenges. Migrants are unable to adapt to the host countries; they are constantly attacked by the host nation as they are accused to be stealing their jobs (Idemudia and Boehnke 2020). In responding to all those turbulences that they are experiencing; they end up resolving to binge drinking and/or smoking. In other instance, they resolve to those coping mechanism in order to appear cool and adopted by the peers on the street. Equally in this study, participants indicated that they left their native country for betterment of their life. However, as they are illegal migrants, they find it difficult to find employment and alcohol helps them to relieve stress (Weyers 2012; Matlakala and Makhubele 2019). This study thus contributes to already existing broader knowledge that there is a clear association between alcohol abuse and stress. The danger is that even when migrants acquire a job, due to their dependence to alcohol, they cannot attain quality of life as alcohol guards against that. 


\section{CONCLUSION}

This study has accentuated how alcohol work against quality of life for migrants' youth. The researchers highlighted that due to the accessibility, availability, affordability of alcohol, and stress, migrants indulge into binge drinking. In most instance, binge drinking is caused by the fear and violence experienced by migrants' youth face in hands of the natives the host country. Just like any other youth, alcohol is seen as a way to cope with all the challenges of life. Before they know it, migrants' youth find themselves dependent to alcohol and unable to send money home (the sending country) to support their loved ones.

\section{AUTHOR CONTRIBUTIONS}

The lead author wrote the manuscript draft. The other authors collected data, edited the manuscript and added literature to make it carry more weight.

\section{FUNDING}

This research was funded by National Institute for the Humanities and Social Sciences (NIHSS).

\section{ACKNOWLEDGEMENT}

This work is based on the research supported by the National Institute for the Humanities and Social Sciences.

\section{REFERENCES}

Ananias, J.A., Makhubele, J.C., Hasheela, M.W., Hamuse, N.I., Freeman, R.J., Mafa, P., Matlakala, F.K., Chilwalo, B.N., Rapholo, S.F., \& Svinurai, A. 2019. "Views of Teachers and Hostel Matrons on the Landscape of Substance Abuse Amongst the Youth in the Northern Region of Namibia." Global Journal of Health Science. 11(5):133-43. https://doi.org/10.5539/gihs.v11n5p133

Anderson, P., \& Baumberg, B. 2006. "Alcohol in Europe-public health perspective: report summary." Drugs: education, prevention and policy, 13(6):483-488. https://doi.org/10.1080/09687630600902477

Bless, C., \& Higson-Smith, C. 2000. Social research methods. An African Perspective. Oxford: Cape Town

Castles, S., \& Miller, M. 2003. The Age of Migration: International Population Movements in the Modern World. Basingstoke, Palgrave-Macmillan.

Center for Victims of Torture. 2015. Reclaiming hope, dignity and respect: Syrian and Iraqi torture survivors in Jordan. Retrieved from http://www.cvt.org/sites/default/files/ attachments/u11/downloads/ReclaimingHope_01042016.pdf

Collins, D., \& Lapsley, H.M. 2008. The costs of tobacco, alcohol and illicit drug abuse to Australian society in 2004/05. Canberra: Department of Health and Ageing. https://doi.org/10.1037/e674312010-001

Connor, T. H., DeBord, D. G., Pretty, J. R., Oliver, M. S., Roth, T. S., Lees, P. S., Krieg Jr E.F., Rogers, B., Escalante, C.P.,
Toennis, C.A., \& Clark, J.C. 2010. "Evaluation of antineoplastic drug exposure of health care workers at three university-based US cancer centers." Journal of Occupational and Environmental Medicine, 52(10), 1019-1027. https://doi.org/10.1097/JOM.0b013e3181f72b63

Gruenewald, P.J., \& Remer, L. 2006. "Changes in outlet densities affect violence rates." Alcoholism: Clinical and Experimental Research, 30(7):1184-1193. https://doi.org/10.1111/j.1530-0277.2006.00141.x

Hasheela, M.W., Ananias, J.A., \& Schenek, C. 2020. "The mushrooming of alcohol establishments: A case study of Greenwell Matongo, Windhoek, Namibia." E-Bangi Journal of Social Sciences and Humanities, 17(8): 190-122. https://doi.org/10.5539/gjhs.v11n10p134

Hasheela, M.W., Makhubele, J.C., Ananias, J.A., Matlakala, F.K., Mafa, P., Chiwalo, B.N., Rapholo, S.F., Freeman, R.J., Svinurai, A., \& Hamuse, M.W. 2019. "Proximity and Density of Alcohol Outlets as a Risk Factor of Alcohol Abuse Amongst the Youth: A Case Study of a Border Town in Northern Region of Namibia." Global Journal of Health Science, 11(10).

Horyniak, D., Melo, J., Farrell, R., Ojeda, V. D., \& Strathdee, S. A. 2016. "Prevalence and risk factors for substance use among refugees, internally displaced people and asylum seekers: findings from a global systematic review." Annals of Global Health, 82(3). https://doi.org/10.1016/j.aogh.2016.04.179

Idemudia, E., \& Boehnke, K. 2020. Psychosocial Experiences of African Migrants in Six European Countries: A Mixed Method Study. Springer. https://doi.org/10.1007/978-3-030-48347-0

Karger, H. 2000. American social welfare policy: A pluralist approach. New York: Longman

Leow, D. M. Goldstein, M., \& McGlinchy, L. 2006. A selective literature review: Immigration, acculturation \& substance abuse. New York City: Education Development Center.

Mafa, P., \& Makhubele, J.C. 2020. "Teenage Substance Abuse: Impact on The Family System and Parents' Coping Strategies." Pertanika Journal of Social Sciences \& Humanities, 28 (3): 1925 - 1938

Makhubele, J.C. 2012. "Social exclusion as a contributing factor for the addition of harmful substances to home-made alcohol: The case of Mopani District in Limpopo Province, South Africa." African Journal of Drug and Alcohol Studies, 11(1).

Matlakala, F.K. 2018. Risk factors of alcohol abuse amongst the youth in Musina town, Limpopo province (Masters' dissertation). University of Limpopo.

Matlakala, F.K., \& Makhubele, J.C. 2019. "Perceptions of church leaders on accessibility and affordability of alcohol abuse amongst youth in Musina Town, Limpopo province." Theologia Viatorum, 43(1):1-5. https://doi.org/10.4102/TV.v43i1.5

Neuman, W.L. 2000. Social research methods: qualitative and quantitative approaches. 4th Edition. Boston: Allyn \& Bacon.

Osuafor, G.N., Maputle, S.M., \& Ayiga, N. 2016. "Patterns of substance use and its predictors among North-West University students Mafikeng campus." African Journal of Drug and Alcohol Studies, 15(2):111-21.

Paton, A. 2005. "Alcohol in the body." Bmj, 330 (7482), 85-87. https://doi.org/10.1136/bmj.330.7482.85

Peltzer, K., \& Pengpid, S. 2008. "Sexual abuse, violence and HIV risk among adolescents in South Africa." Gender and Behaviour, 6(1):1462-1478. https://doi.org/10.4314/gab.v6i1.23360

Peltzer, K., Ramlagan, S., Johnson, B.D., \& Phaswana-Mafuya, N. 2010. "Illicit drug use and treatment in South Africa: a review." Substance use \& misuse, 45(13):2221-2243. https://doi.org/10.3109/10826084.2010.481594 
Ramlagan, S., Peltzer, K., \& Phaswana-Mafuya, N. 2013. "Social capital and health among older adults in South Africa." BMC geriatrics, 13(1):100. https://doi.org/10.1186/1471-2318-13-100

Setlalentoa, B. M. P., Pisa, P. T., Thekisho, G. N., Ryke, E. H., \& Loots Du, T. 2010. "The social aspects of alcohol misuse/abuse in South Africa." South African Journal of Clinical Nutrition, 23(sup2), 11-15. https://doi.org/10.1080/16070658.2010.11734296

Setlalentoa, M., Ryke, E., \& Strydom, H. 2015. "Intervention strategies used to address alcohol abuse in the North West province, South Africa." Social Work, 51(1):80-100. https://doi.org/10.15270/51-1-429
Weyers, M.L. 2012. The Theory and Practice of Community Work: A southern African Perspective. $2^{\text {nd }}$ Edition. Keurkopie.

World Health Organization [WHO]. 2002. National cancer control programmes: policies and managerial guidelines. Geneva: World Health Organization.

World Health Organization. 2019. Global status report on alcohol and health 2018. Geneva: World Health Organization.

https://doi.org/10.6000/1929-4409.2021.10.139

(c) 2021 Matlakala et al.; Licensee Lifescience Global.

This is an open access article licensed under the terms of the Creative Commons Attribution Non-Commercial License (http://creativecommons.org/licenses/by-nc/3.0/) which permits unrestricted, non-commercial use, distribution and reproduction in any medium, provided the work is properly cited. 